International Journal of Food Science, Nutrition and Dietetics (IJFS)

ISSN 2326-3350

\title{
The Nutritional Status of Diabetic Nephropathy Patients Undergoing Hemodialysis at New Delhi Hospital, India: A Pilot Study
}

Anjali'i*, Veenu Seth ${ }^{2}$

Research Article

${ }^{1}$ Department of Food \& Nutrition, Lady Irwin College, Delhi University, New Delhi, India.

${ }^{2}$ Retd. Faculty, Department of Food \& Nutrition, Lady Irwin College, Delhi University, New Delhi, India.

\begin{abstract}
Diabetic nephropathy, one of the complications resulting from uncontrolled diabetes can lead to end stage renal disease (ESRD), which in such diabetics often necessitates dialysis. Dialysis can further have an adverse impact on the nutritional status. Hence, the study sought to assess the nutritional status of diabetic nephropathy patients undergoing haemodialysis. This cross sectional pilot study data was derived from 30 Diabetic nephropathy patients undergoing haemodialysis, aged 40-75 years of either sex. Demographic Questionnaire, 24 hour diet recall, Food Frequency Questionnaire and case records constituted the data collection tools. Dietary intake revealed inadequacies of several food groups except cereal, milk and eggs. Food selection from each group reflected incomplete knowledge, ranging from poor to fair knowledge of relevant nutrients sources. Variable nutrient intake reflected inadequacies of energy, calcium, niacin, folic acid, vitamin A and vitamin C, whereas protein, potassium, phosphorus, thiamine and riboflavin were fairly adequate. Salient findings of the study also revealed anorexia, oliguria and oedema as common symptoms along with several biochemical aberrations.Subjects of diabetic nephropathy had insufficient nutritional intake. Hence nutritional assessment and diet counselling is critical in such patients, so that appropriate diet therapy can be prescribed.
\end{abstract}

Keywords: Diabetes; Diabetic Nephropathy; Haemodialysis; ESRD.

\section{*Corresponding Author:}

Anjali,

Department of Food \& Nutrition, Lady Irwin College, Delhi University, B-297, Qutub Vihar, Phase-1, New Delhi-110071, India.

Tel: +91-9971267238

E-mail: anjalijuly7@gmail.com

Recieved: November 28, 2014

Accepted: January 21, 2015

Published: January 22, 2015

Citation: Anjali, Veenu Seth (2015). The Nutritional Status of Diabetic Nephropathy Patients Undergoing Hemodialysis at New Delhi Hospital, India: A Pilot Study. Int J Food Sci Nutr Diet. 04(1), 178-182. doi: http:// dx.doi.org/10.19070/2326-3350-1500033

Copyright: Anjali $^{\odot}$ 2015. This is an open-access article distributed under the terms of the Creative Commons Attribution License, which permits unrestricted use, distribution and reproduction in any medium, provided the original author and source are credited.

\section{Introduction}

Today, unprecedented economic development and rapid urbanization in Asian countries, particularly in India has led to a shift in health problems from communicable to non-communicable diseases. Of all the non-communicable diseases, diabetes and cardiovascular diseases lead the list [1]. Diabetes earlier considered a disease of minor significance to world health, is now taking its place as one of the main threats to human health in the $21^{\text {st }}$ century [2]. Diabetes if not controlled properly, can lead to increased risk of developing series of long term complications like heart disease, stroke, kidney failure, blindness, amputations and other conditions related to poor blood circulation. Diabetes is the most common cause of kidney failure due to development of Diabetic nephropathy. Around $20 \%$ to $30 \%$ of diabetics are known to develop End Stage Renal disease (ESRD) in their lifetime [3,4] which requires dialysis. Dialysis, besides ESRD, can further have an adverse impact on their nutritional status. Several studies have also reported insufficient dietary and nutrient intake among these patients [5-8]. Therefore diet management plays a central role in good diabetes management and requires lifelong behaviour change with respect to diet and other lifestyle factors like physical activity, smoking, alcohol [9] to avoid complications. Assessment of nutritional status can provide valuable information concerning nutrient intake and requirements of diabetics and can identify patients who are at risk for various nutritional disorders. Ironically, there is a paucity of data and research efforts on nutritional profile of renal patients in India and no research efforts are insight, except for a few limited studies. Therefore this study aimed to assess the nutritional profile of the diabetic nephropathy patients on haemodialysis.

\section{Methods}

This cross sectional pilot study was conducted in a super specialty hospital of New Delhi, India to assess the nutritional status of the diabetic nephropathy patients undergoing haemodialysis. Thirty such patients aged 40-75 years, who were undergoing haemodialysis for about 1-3 years were selected via purposive sampling. Ethical clearance was obtained from the institutional ethical committee of Lady Irwin College, New Delhi for the study. The pur- 
pose, objectives and the methodology of the study were explained to the subjects and written consent for participation in the study was obtained from them.

Background information of the patients was collected through a pretested questionnaire. Malnutrition is a relatively common problem among ESRD patients on conservative management or on dialysis. It can be secondary to poor nutrient intake, increased losses in body composition and increased protein catabolic rate. For all these reasons nutritional assessment is of paramount importance which can be done by various methods which are interlinked to each other. Therefore all the parameters like anthropometrics, biochemical measurements, clinical as well the dietary measurements were assessed. Anthropometric measurements and biochemical parameters were obtained from the case records. Dietary recall and food frequency questionnaire to validate the dietary recall was used to evaluate the nutrient intake. The 24-h recall consisted of a detailed discussion of what foodstuffs and dishes had been eaten and in what quantity during the preceding day. It was conducted for one day because of paucity of time. The visits were unannounced. Food intake was not measured on festival days, when special foods are eaten. To serve as a framework of the dietary interview the general format of the dietary recall was given. All the foodstuffs and dishes and their amounts were recorded meal by meal. The interviewee was allowed to designate the size of the servings by units of weight, volume or household measure or with the aid of the food models. Conversion of cooked food to raw food weight to grams was done later using standardized measurements. Dry spices and condiments were not included in calculations. The food frequency questionnaire was also used to assess the frequency with which food items or food groups were consumed. The questionnaire consisted of a list of foods and an associated set of frequency of use response categories. The list of food items focused on particular foods, or foods consumed commonly. The frequency of response categories were daily, weekly, fortnightly and number of times in each of these categories, along with the amount eaten. All tools were pretested before using for data collection.

\section{Data Analysis}

In order to estimate the exact quantity of food consumed by the subjects, cooked food amounts in household measures were converted to raw weights of different food stuffs. For this, the recipes standardized at Lady Irwin College were used [10,11]. The nutri- ent content of the raw food intake for one day was then calculated using the Nutritive Value of Indian Foods [12].These values were compared with KDOQI guidelines for diabetic nephropathy patients on dialysis which were also being used at the hospital. The food group adequacy was determined by using National Kidney Foundation (NKF) guidelines [13] as the hospital did not have any recommendations for the food group intake. The data was analysed using SPSS Statistics 16.0 as the statistical software. Analysis was done on the basis of means, frequency distribution and percentages.

\section{Results and Discussion}

\section{Sample Characteristics}

A total of 30 diabetic nephropathy patients who were visiting the renal OPD of a Superspeciality Hospital in New Delhi for haemodialysis during the period of the study were recruited for the study. Majority of the subjects ( 15 males, 5 females) were in the age range of 55-65 years, with fewer subjects in the 45-55 years age range. Total number of male subjects was 23 and only 7 were female patients. All 30 subjects were literate.

\section{Disease Profile}

Most of the subjects ( $83 \%$ ) reported the onset of diabetes $\geq 5$ years and the remaining for less than five years. The onset of kidney disease in $90 \%$ of subjects was < 5 years, while in $10 \%$ subjects the onset was more than 5 years. Sixty three percent subjects had been on dialysis within the past one year, whereas rests were on dialysis between $1-3$ years.

\section{Anthropometric Measurements}

According to WHO [14] classification, 6.6\% of the subjects were grouped under the underweight category. About $39.6 \%$ of the subjects were found to have normal BMI. The percentages of the subjects falling under the category of overweight and obese were $23.1 \%$ and $29.7 \%$, respectively. The mean weight and body mass index value (Table 1) for both male and female subjects were found to be higher as compared with the standards. The reason for mean higher BMI was that most of the patients were overweight prior to the initiation of haemodialysis also, and this was possibly caused by fluid retention in $90 \%$ subjects.

Table 1. Mean value of anthropometric measures of subjects

\begin{tabular}{|l|l|l|}
\hline Anthropometric measures & \multicolumn{3}{|l|}{ Range } & Mean \pm SD \\
\hline Weight (in kgs) & $38.00-116$ & $66.4 \pm 15.9$ \\
\hline Male & $42.8-96.2$ & $70.6 \pm 20.1$ \\
\hline Female & $155.1-177.9$ & $165.8 \pm 7.4$ \\
\hline Height (in cms) & $152.5-162.7$ & $158.3 \pm 3.8$ \\
\hline Male & \multicolumn{3}{|l|}{} \\
\hline Female & $15.4-41.7$ & $24.4 \pm 6.0$ \\
\hline BMI $\left(\mathrm{kg} / \mathrm{m}^{2}\right)$ & $18.5-38.4$ & $28.3 \pm 7.7$ \\
\hline Male
\end{tabular}

Results are expressed as Mean \pm standard deviation $(\mathrm{n}=30)$ 


\section{Biochemical Profile}

Values for various biochemical parameters like phosphorus, urea, creatinine and alkaline phosphatase (Table 2) were significantly higher than the normal values in these subjects. The haemoglobin level in both males and females was low, $10.0 \pm 1.4 \mathrm{~g} / \mathrm{dl}$ and 8.8 $\pm 1.7 \mathrm{~g} / \mathrm{dl}$ respectively, indicating prevalence of renal anaemia.
Cho [15] et al. also investigated biochemical parameters for 110 HD patients (46 males and 64 females) and found that about $50.9 \%$ patients had anaemia (haemoglobin: $<11.0 \mathrm{~g} / \mathrm{dl}$ ). The mean values of the fasting blood glucose were also high, which is a cause of concern as optimal glycemic control is crucial for retarding the progression of the renal disease.The mean systolic pressure washigher while the diastolic pressure was found to be

Table 2: Mean biochemical parameter values of subjects $(n=30)$

\begin{tabular}{|l|l|l|}
\hline Parameters & Range & Mean \pm SD \\
\hline Sodium $(\mathrm{mEq} / \mathrm{l})$ & $128-140$ & $135.4 \pm 2.8$ \\
\hline Phosphorus $(\mathrm{mg} / \mathrm{dl})$ & $3.6-12$ & $5.9 \pm 1.8 \#$ \\
\hline Potassium $(\mathrm{mEq} / \mathrm{l})$ & $3.4-6.8$ & $4.70 \pm 0.9 \#$ \\
\hline Calcium $(\mathrm{mg} / \mathrm{dl})$ & $5.7-9.9$ & $8.2 \pm 0.9$ \\
\hline Urea $(\mathrm{mg} / \mathrm{dl})$ & $40.7-192.6$ & $115.9 \pm 35.9 \#$ \\
\hline Creatinine $(\mathrm{mg} / \mathrm{dl})$ & $3.00-14.00$ & $6.9 \pm 2.4 \#$ \\
\hline Hemoglobin $(\mathrm{g} / \mathrm{dl})$ & Males 7.8-13.8 & Males 10.0 \pm 1.4 \\
& Females7.1-11.3 & Females $8.8 \pm 1.7$ \\
\hline Total Protein $(\mathrm{g} / \mathrm{dl})$ & $5.4-9.0$ & $6.8 \pm 0.8$ \\
\hline Albumin $(\mathrm{g} / \mathrm{dl})$ & $2.1-4.1$ & $3.2 \pm 0.5$ \\
\hline Globulin $(\mathrm{g} / \mathrm{dl})$ & $2.2-5.3$ & $3.6 \pm 0.7 \#$ \\
\hline ALP $(\mathrm{U} / \mathrm{L})$ & $49-349$ & $130.3 \pm 73.6 \#$ \\
\hline Total binding capacity $(\mu \mathrm{g} / \mathrm{dl})$ & $182-411$ & $270.1 \pm 55.7$ \\
\hline Transferrin saturation $(\%)$ & $11.1-67.8$ & Males 23.9 \pm 13.2 \\
& $7.8-29.4$ & Females $14.9 \pm 7.0$ \\
\hline Fasting blood sugar $(\mathrm{mg} / \mathrm{dl})$ & $\begin{array}{l}\text { Males } 90-20 \\
\text { Females 120-290 }\end{array}$ & $\begin{array}{l}\text { Males } 143.5 \pm 35.2 \# \\
\text { Females } 197.5 \pm 80.9 \#\end{array}$ \\
\hline Systolic blood pressure $(\mathrm{mmHg})$ & Males 114-194 & Males 143.9 $\pm 21.6 \#$ \\
& Females 120-180 & Females 149.9 $\pm 18.6 \#$ \\
\hline Diastolic blood pressure $(\mathrm{mmHg})$ & Males 53-97 & Males 70.1 \pm 11.6 \\
& Females 60-101 & Females 78 \pm 13.9 \\
\hline
\end{tabular}

Results are expressed as Mean \pm standard deviation $(\mathrm{n}=30)$

\# Values indicate higher than the normal range*

*Mahan and Stump,2008

on lower side. The albumin level $(3.2 \pm 0.5 \mathrm{~g} / \mathrm{dl})$ was found to be low in the subjects. The study results were found to be similar with the study done by Alshatwi [7] et al. who evaluated the biochemical parameters of 61 haemodialytic patients and found that $60 \%$ of patients had a serum albumin level of less than $3.5 \mathrm{~g} / \mathrm{dl}$. The mean serum albumin level was $3.2 \pm 0.5 \mathrm{~g} / \mathrm{dl}$ which was substantially lower than the normal range. Serum albumin is a strong indicator of protein intake, thus reflecting a possibly low intake of protein in these patients. This also suggests that adequate nutritional intakes of protein and energy are essential for maintaining the visceral protein stores [16].

\section{Clinical Measurements}

Loss of appetite, decrease in urine output and puffiness of eyes and ankles were the most common symptoms (90\%, 87\% and $90 \%$, respectively) followed by dizziness and occasional unconsciousness. Fatigue, nausea, trembling was also present (Figure 1).

\section{Dietary Intake}

Food Groups Intake: The intake of various food groups was variable.
- Cereal: The cereal intake was found to be almost adequate and most commonly consumed foods were wheat flour, broken wheat, brown bread, semolinaand oats among the subjects.

- Pulse: The mean pulse intake obtained from 24 hour recall was $26.2 \pm 18.1 \mathrm{~g}$ indicating some variability in intake. Though there are no recommendations given by National Kidney Foundation's guidelines [14] for pulse intake, but it can increase the palatability of the renal diet, particularly in the Indian context and thereby help in ensuring adequate energy intake. The pulses that were being frequently consumed included split and dehusked pulseslike red gram, bengalgramand green gram.

- Vegetables and Roots and Tubers - Among the vegetables and roots and tubers, cauliflower, bottle gourd, Indian round gourd, peas, brinjal, capsicum, bitter gourd, onion, and potato were the foods that were being frequently consumed. The consumption of both vegetables and roots and tubers was found to be inadequate. The selection of the vegetables indicated that the subjects had some knowledge regarding nutrient sources as most of the vegetables consumed were low in both sodium and potassium.

- $\quad$ Fruits: The fruit intake was inadequate because lack of aware- 
Figure 1. Clinical signs and symptoms of the Disease among the subjects $(n=30)$

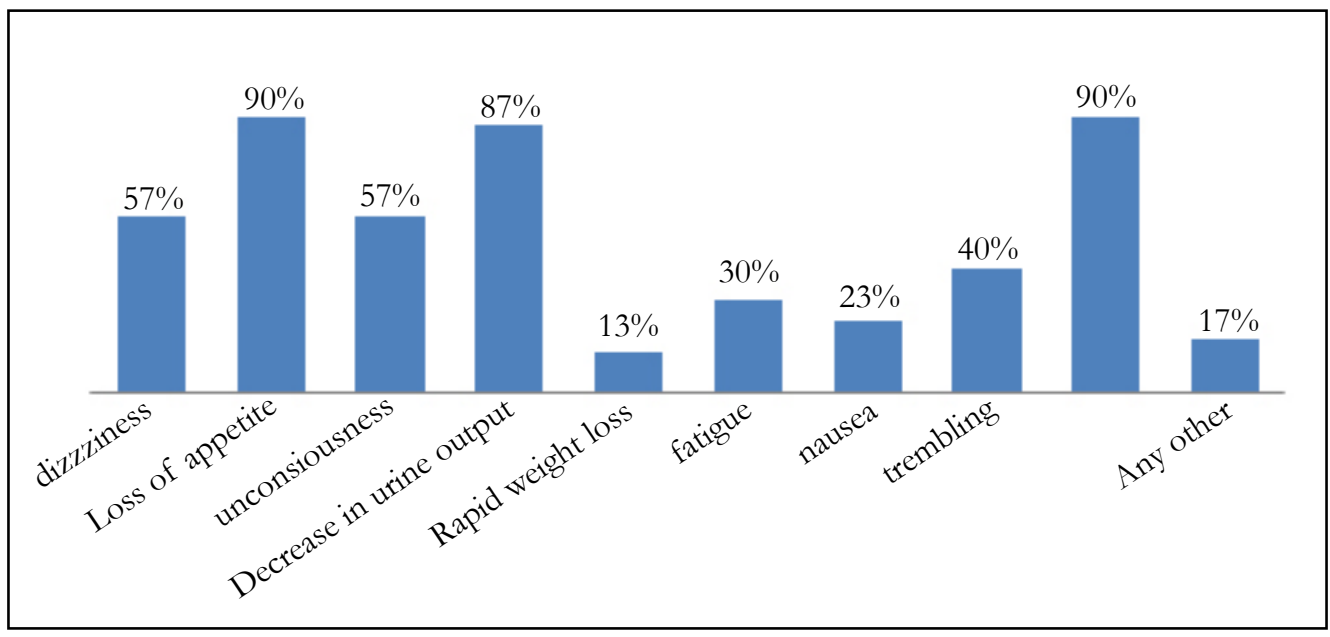

ness regarding the potassium content of fruits. Though the subjects were consuming low potassium fruits but there was lack of variety in the consumption of fruits. Thus, there was a need to make them aware about appropriate selection and variety of fruits, especially with respect to potassium.

- $\quad$ Milk and Milk Products: Among the milk and milk products milk, yogurt and cottage cheese were being frequently consumed as these are a source of HBV protein and therefore good for haemodialysis patients, as communicated to them by the dietician or doctor. The mean intake of milk and milk products was adequate.

- Meat and Meat Products: The mean intake of meat and meat products was $48.8 \pm 40.6 \mathrm{~g}$ reflecting wide variation in intake. All the subjects were consuming eggs and the reason for the daily intake of eggs was the advice given by the doctor and the dietician that egg is a good source of protein.

- Fats: Daily intake of fat was inadequate in these subjects. All the subjects were however, using combination of various fats, especially oils, which is desirable.

- Sugars: For sugar, the intake was almost negligible as these patients were diabetics and the sugar is restricted in their diets.

Food selection within each group reflected variable knowledge of nutrients sources ranging from poor to fair, thereby indicating a need of educational intervention/counselling among them.

\section{Nutrient Intake}

Some imbalances were observed with respect to nutrient intake (Figure 2).

- Energy: The nutritional adequacy for energy was only $56.3 \%$ which was inadequate. Thus, it is important to eat enough quantity of food to provide the necessary calories to minimize endogenous protein breakdown. The causes of low energy intake were lack of appetite, several dietary restrictions, and inability to select appropriate foods.

- Protein: The mean intake was inadequate at $0.8 \pm 0.3 \mathrm{~g} / \mathrm{kg} / \mathrm{d}$. The mean percentage of HBV protein in subject's diet was $41.2 \% \pm 13.6$ with the range of $7.2-71.1 \%$ and only $16.6 \%$ subjects were consuming more than $50 \%$ of $\mathrm{HBV}$ protein. $\mathrm{HBV}$ protein is important for these patients as it minimizes urea production.

- Carbohydrates: The mean carbohydrate percent adequacy was found to be $90 \%$, with the mean energy percentage contribution of $58.6 \% \pm 7.1$, ranging from $36.5-73.2 \%$ which show a wide range of variation among the subjects.

- Fat: The mean percentage contribution of fat to the total energy was only $25.0 \pm 6.7 \%$. Thus, fat intake could be increased upto $30 \%$ energy in these individuals as fats being energy dense, contribute to a large extent to the overall energy, which was deficient in these subjects.

- Sodium: The mean intake of sodium from the food stuffs was also variable, with a mean intake of $356.9 \pm 185.9 \mathrm{mg} /$ day which was well within the recommended amount and there was a provision of including about $3 / 4$ of teaspoon salt. Sodium restriction is important, as excessive sodium intake is responsible for increased thirst, increased fluid gain, and hypertension. However, judicious use of salt within permissible limits can increase palatability of food and this can help increase food and hence energy intake.

- Potassium: The mean daily intake and level of adequacy of potassium was appropriate as compared with the recommended amount. This could further aggravate renaldisorder.

- Calcium and Phosphorus: The percent adequacy of calcium was $39.6 \%$ which is very low and for phosphorus it was $108.2 \%$ which is little on the higher side which can lead to hyper phosphatemia.

- Iron: The mean intake of iron was $12.4 \pm 4.0 \mathrm{mg} /$ day with the range of $7.0-23.9 \mathrm{mg} /$ day. About $53.3 \%$ subjects had low iron intake. Thus to prevent iron deficiency in them appropriate supplements are required.

- Other Vitamins and Minerals: Among micronutrients, thiamine and riboflavin were found to be fairly adequate with the percent adequacy of $102.7 \%$ and $81.8 \%$, respectively, whereas niacin, folic acid, vitamin $\mathrm{A}$ and vitamin $\mathrm{C}$ were quite low in terms of their percent adequacy.

\section{Conclusion}

It may thus be concluded from this study that subjects of diabetic nephropathy faced several biochemical aberrations. Their poor diet intake was associated with poor nutritional adequacy. The limited data generated by this pilot study has however provided insight and useful information required for patient management in diabetic nephropathy patients undergoing dialysis. This study highlights the importance of empowering patients with diet related knowledge to facilitate self-care and minimize problems faced on a day to day basis. The need for regular and sustained coun- 
Figure 2. Mean percent adequacy for different nutrients among the subjects $(n=30)$

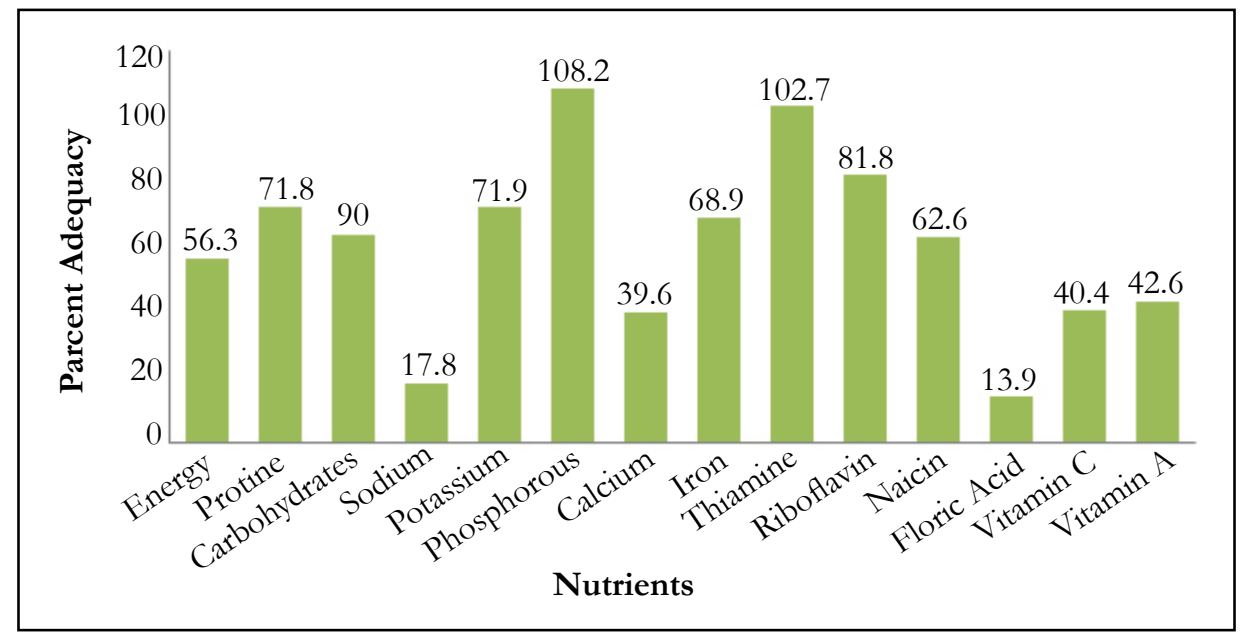

selling, especially dietary counselling for better patient outcome cannot be over looked. The study also brings out the need for improvement of nutritional status of diabetic nephropathy patients on maintenance haemodialysis. Every maintenance dialysis patient needs an intensive nutritional counselling based on an individualized plan of care developed before or at the time of commencement of maintenance dialysis therapy. Monitoring of body weight and body mass index to manage progressive loss of weight even in overweight patients is required. Regular assessment of nutritional status of patients undergoing maintenance haemodialysis every three to six months would be beneficial to identify patients at malnutrition risk, and allow for early nutritional intervention.

\section{Acknowledgement}

The authors sincerely thank the study participants for their contribution to the research, as well as staff of Dialysis unit, Max Super Specialty Hospital, New Delhi. We would also like to thank to Ms. Ritika Samadhar, Regional Head, Dietetics, and Dr. Riyaz Ahmad Asad (Senior Resident), Max Healthcare, Saket New Delhi. The authors would specifically like to show the gratitude to Dr. Anupa Siddhu, Director, Lady Irwin College for providing institutional support and encouragement.

\section{Ethical Approval}

The study was approved by the institutional ethics committee of Lady Irwin College, University of Delhi. Informed consentwas obtained from the individuals prior to inclusion in the study.

\section{References}

[1]. IDF, International Diabetes Federation. (2009). Diabetes Atlas.4th ed. Brussels, Belgium: International Diabetes Federation: 21-27.

[2]. Zimmet P (2000) Globalization, coca-colonization and the chronic disease epidemic: can the doomsday scenario be averted? J Intern Med 247:
$301-310$.

[3]. Lee G (2003) End-stage renal disease in the Asian-Pacific region.SeminNephrol 23(1):107-114.

[4]. Prabhar MR, Chandrasekran V, Soundararajan P (2008) Epidemic of chronic kidney disease- what can be done? Saudi J Kidney Dis Transpl 19 (5): $847-853$.

[5]. Schneeweiss B, Graninger W, Stockenhuber F, Druml W, Ferenci P, et al. (1990) Energy Metabolism in acute and chronic renal failure. Am J Clin Nutr 52: 596-601.

[6]. Locatelli F, Andrulli S, Memoli B, Maffei C, Vecchio LD, et al. (2006) Nutritional inflammation status and resistance to erythropoietin therapy in haemodialysis patients. Nephrol Dial Transplant 2: 991-998.

[7]. Alshatwi AA, Alshmary A, Abdrohman A (2007) Nutritional assessment of hemodialysis patients.J Med Sci 7(2): 294-298.

[8]. Ashabi A, Tabibi H, Houshair A, Heshnati B, Mitra MM (2011) Dietary assessment of hemodialysis patients in Tehran, Iran. HemodialInt 15(4): 530-537.

[9]. ADA (2011) American Dietetic Association. Executive Summary: Standards of Medical Care in Diabetes. Diabetes Care, 34 (supp 1): 4-10.

[10]. Raina U, Kashyap S, Narula V, Thomas S, Suvira S, et al. (2010) Basic Food Preparation: A Complete Manual.Orient Blackswan 22-23.

[11]. Sharma M (2009) Dietary assessment of diabetic adolescents (12-19 years): Development of a self-care diet management tool. Department of Home Science, Lady Irwin College: Delhi University.

[12]. ICMR (2010) Indian Council of Medical Research.Nutrient requirements and recommended dietary allowances for Indians. NIN. Hyderabad.

[13]. NKD guidelines for hemodialysis patients. (2012) URL: http://www.kidney.org/.

[14]. Cho JH, Hwang JY, Lee SE, Jang SP, Kim WY (2008) Nutritional status and the role of diabetes mellitus in hemodialysis patients. Nutrition Research and Practice 2(4): 301-307.

[15]. Qureshi AR, Alvestrand A, Danielsson A, Divino-Filho JC, Gutierrez A, et al. (1998) Factors predicting malnutrition in hemodialysis patients: A crosssectional study. Kidney Int 53:773-782.

[16]. Mahan LK (2012) Escott-Stump S, Raymond JL.Krause's Food \& the Nutrition Care Process (Food, Nutrition \& Diet Therapy (Krause's).(13th edtn) Saunders Elsevier. 799-831. 